\title{
E-business Performance and Strategy Planning E-Valuation Based on Adaptive Algorithmic Modelling Methods: Critical Factors Affecting E-Valuation and Strategic Management Methodologies
}

\author{
Alexandra Lipitakis, Evangelia A.E.C. Lipitakis* \\ Kent Business School, University of Kent, Canterbury, Kent CT2 7PE, England \\ *Corresponding Author: eael2@kent.ac.uk
}

Copyright (C) 2014 Horizon Research Publishing All rights reserved.

\begin{abstract}
This article describes an innovative e-business strategy planning e-valuation approach, based on adaptive algorithmic modeling methods for solving a wide class of e-business and strategic management problems. The proposed methodology is based on basic ideas and concepts of four key-field interrelated sciences, i.e. Computing Science, Applied Mathematics, Management and Economic Sciences. Furthermore, the fundamental scientific concepts of adaptability and uncertainty are shown to play a critical role of major importance for a (near) optimum solution of a class of complex e-business/services and strategic management problems. A characteristic case study of adaptive algorithmic schemes containing several distinct e-valuation procedures corresponding to e-business performance models under certain environmental pressures, organizational constraints and describing the relationships between technology, innovation and firm performance, is presented in the proposed adaptive algorithmic modeling approach. The new hybrid algorithmic model includes six dynamic modules, can be optimized and used effectively in e-business performance and strategic planning e-valuation of various e-services in very large organizations. This new methodology incorporating critical factors for e-business performance can play a significant role of major importance for (near) optimum solutions of a class of complex e-business/services and strategic management problems.
\end{abstract}

Keywords Adaptive Algorithms, Adaptivity Principle, Algorithmic Modeling, E-Business Problems, E-Service Strategy Management Methodologies, E-Valuation Of E-Business, Hybrid Algorithmic Modeling, Strategy Management Methodologies, Uncertainty Principle

\section{Introduction}

During the last decades significant research efforts have been focused in important scientific and technological topics related to the fundamental principles of adaptability and uncertainty (Heisenberg et al., 1927-1930; Polya, 1945; Kahneman et al., 1982; Zadeh, 1983; Pelletier et al., 2003; Halpern, 2005; Babuska et al., 2005; Byron et al., 2007).

These two fundamental principles have been extensively used in various methodologies and techniques in a wide spectrum of scientific and technological fields, including physics, statistics, engineering, information science, economics, finance, sociology, philosophy, psychology, insurance, management science, decision theory, e-business and internet applications, and other qualitative and quantitative fields (Brynjolfsson, 1993; Porter, 2001; Wheeler, 2002; NSF, 2006-2011; Grote, 2009). In the following sections we present synoptically the definitions, basic characteristics and applications of these significant fundamental principles in science, technology and social environments. Specifically, the important issues of adaptive algorithmic approach (adaptivity) and singular perturbation concept (uncertainty) for e-business problems and strategic management methodologies in various Digital Information Management (DIM) applications including e-services will be synoptically presented.

\section{The Algorithmic Approach}

The basic concepts of the adaptive algorithmic approach on e-business problems and strategic management methodologies have been recently presented (Lipitakis, 2007a-2007b; Lipitakis and Phillips, 2007).

It is known that an algorithm can be simply defined as a finite set of rules which leads to a sequence of operations for solving specific types of problems, with the following five important characteristic features: finiteness, definiteness, input, output and effectiveness, as described in the classic book of Knuth (Knuth, 1968). The algorithms can be easily presented by the so-called 
'pseudo-algorithmic' form, that is also called 'pseudoalgorithm' or 'pseudocode' in the case of preparation computer programs/codes.

In view of these facts the usage of the adaptive algorithms, with their previously mentioned advantages and the additional important features of compactness, adaptiveness and incorporation of singular parameters that allow the computation of (near) optimum solutions, can be extended for the efficient solution of e-business and Strategic Management (SM) problems and in a wide area of corresponding applications, a part of which is presented in the references and bibliography section (Chaffee, 1985; Dutton et al., 1987; Filkestein and Hambrick, 1996; Teece et al., 1997; Nohria et al., 2003; Coltman et al., 2007; Hafeez et al., 2006; Coltman et al., 2008; Montgomery, 2008).

The term 'adaptive algorithm' denotes here an algorithm which changes its behavior based on the available resources. The adaptive algorithm functions provide a way to indicate the user's choice of adaptive algorithm and let the user specify certain properties of the algorithm. The concept of adaptive algorithm is closely related to the corresponding concept of 'adaptive' or 'variable' choices of the parameters (input elements) of the algorithm. Adaptive algorithms are algorithms that adapt to contention, often have adjustable steps that repeat (iterate) or require decisions (logic or comparison) until the task is completed, are simple and easy to program. The general technique of adapting simple algorithmic methods to work efficiently on difficult parts of complex computational problems can be a powerful one in the algorithm design, evaluation and practice (Lenz, 1981; Barr et al., 1992; Zajac et al., 2000; Brynjolfsson and Hitt, 2000; European Commission, 2004a-2004b; Carton and Hoffer, 2005; Teece, 2006).

\section{The Singular Perturbation Concept}

During the last decades considerable research effort has been focused in studies of initial/boundary-value problems and the behaviour of the approximate solutions of the resulting linear systems by considering a small positive perturbation parameter, affecting the derivative of highest order (Tikhonov and Arsenin, 1963; Lipitakis, 2006).

Following this approach, a class of generalized fully parameterized singularly perturbed (sp) non-linear initial and boundary value problems can be considered and the way that the sp parameters variation affects their numerical solution can be studied (Lipitakis, 2006). For example, let us consider the following fully parameterized non-linear parabolic P.D.E. in two space variables:

$$
\begin{gathered}
\varepsilon_{\mathrm{t}} \frac{\partial \mathrm{u}}{\partial \mathrm{t}}-\varepsilon_{\mathrm{L}} \Delta \mathrm{u}(\mathrm{x}, \mathrm{y})=\alpha \mathrm{e}^{\beta \mathrm{u}(\mathrm{x}, \mathrm{y})} \\
(\mathrm{x}, \mathrm{y}) \in \Omega, \mathrm{t}>0,
\end{gathered}
$$

with initial conditions:

$$
\mathrm{u}(\mathrm{x}, \mathrm{y}, 0)=\mathrm{g}_{0}(\mathrm{x}, \mathrm{y}), \quad 0 \leq \mathrm{x}, \mathrm{y} \leq 1,
$$

and boundary conditions:

$$
\mathrm{u}(\mathrm{x}, \mathrm{y}, \mathrm{t})=\mathrm{g}_{\mathrm{t}}(\mathrm{x}, \mathrm{y}), \quad \mathrm{t}>0,
$$

where $\varepsilon_{t}$ and $\varepsilon_{\mathrm{L}}$ are sp-parameters affecting the derivative with respect to time and the derivatives with respect to the space variables respectively, and $\Delta$ is the known Laplacian operator (Lipitakis, 2006).

The real parameters $\alpha$ and $\beta$ affect the non-linear term, while certain values of these parameters lead to highly non-linear terms. It can be easily seen that for various values of the given parameters $\varepsilon_{t}, \varepsilon_{\mathrm{L}}, \alpha$ and $\beta$, a wider class of non-linear P.D.E.'s can be considered and eventually solved by following the proposed computational solution techniques. Furthermore, the equation (1.1) for the special case $\varepsilon_{\mathrm{t}}=\varepsilon_{\mathrm{L}}=\alpha=\beta=1$, reduces to a simple non-linear parabolic equation in two space variables. It should be noted that the sp-parameters have been firstly used by Tikhonov for solving numerically singularly perturbed ordinary differential equations (Tikhonov, 1936).

In this article we show that suitable adaptive algorithmic procedures can be efficiently used for solving a wide class of complex computational problems, including e-business and strategic management problems. Furthermore, we point out that the selective usage of both algorithmic and sp-concepts, i.e. the usage of adaptive algorithms in combination with the dynamical choice of sp-parameters, can lead to (near) optimized solutions. The applicability of the proposed adaptive algorithmic approach and sp-concept methodology is demonstrated by considering a characteristic case study in e-publishing business applications.

The fundamental principles of adaptivity and uncertainty have been extensively used in various methodologies and techniques in a wide spectrum of scientific and technological fields, including physics, statistics, engineering, information science, economics, finance, sociology, philosophy, psychology, insurance. A thorough investigation reveals the fact that a little attention has been comparatively given to the important topics of management science, decision theory, e-business and internet applications, and other qualitative and quantitative fields (Brynjolfsson, 1993; Porter, 2001; Wheeler, 2002; Grote, 2009) concerning the efficient application of adaptivity and uncertainty principles to these significant areas and their multidimensional applications. In the following section we synoptically discuss on the fundamental adaptivity and uncertainty principles.

\section{On the Adaptivity and Uncertainty Principles}

In the following section we present synoptically the definitions, basic characteristics and applications of the adaptivity and uncertainty principles in science, technology and social environments.

\section{Adaptation and its capabilities}

The general term of adaptation (in Computer Science) refers to a special process in which certain interactive 
(adaptive) systems can adapt their behavior to individual users based on information acquired about their users and their corresponding environments.

The process of adaptation usually includes the following sub-categories: (i) Adaptability, (ii) Adaptivity, (iii) Personalization and (iv) Extensibility (Rashey et al., 1997; Graf, 2007). The main adaptation capabilities are related to the categories of adaptivity and adaptability. The former indicates (adaptive) systems that can adapt automatically to their users according to certain changing conditions, while the latter refers to users that can customize the (adaptable) systems through several tailoring activities by themselves. These system categories are considered to be complementary to each other (Opperman, 2005).

A synoptic description of the adaption capabilities of the previous categories can be given as follows (Graff, 2007; Rashey and Kinshuk, 1997; Subramanan et al., 1999):

(i) Adaptability: includes all the necessary facilities to customize the system for the educational organization requirements and needs,

(ii) Adaptivity: indicates all forms of automated adaptation to the individual learners' requirements and needs,

(iii) Personalization: indicates the facilities of users to customize their personal views (language's designs) of the system,

(iv) Extensibility: generally for all open source products with difficulties in the actual application.

\section{The Adaptivity Principle}

The Adaptivity Principle, a part of its multidimensional applications in almost every scientific and technological field and a wide spectrum of their applications including several multiple transformation processes, can be used as an important tool in several e-learning environments in order to overcome various basic e-learning barriers and complementary help to spread e-learning among large classes of users (Kareal et al., 2006; Paramythis et al., 2004).

Dynamic adaptivity is considered to be one of the most challenging non-functional issues of the advanced information systems engineering indicating the capability of systems (or software) to make certain changes during their execution related to various aspects of architectural, functional, structural, content and service levels (Raibulet, 2008; Raibulet et al., 2009).

\section{Adaptability}

Adaptability is a characteristic feature of a process or of a system and is considered to be an important factor for the efficiency and economic success of business and manufacturing systems (Andresen et al., 2005; Andresen, 2006).

In the case of life sciences adaptability can have several meanings, such as understanding or information entropy measure of biota of certain ecosystems, such as populations of species, genes, proteins, cells etc. (Conrad, 1983). In the case of biological and ecological systems adaptability and efficiency, although are important factors for the evolution of such systems, can be interpreted to be in opposition to each other. The adaptability of a process or a system can be determined by validating certain predetermined criteria. In the technical and technological research fields the factor of adaptability is considered an important factor for manufacturing and system engineers (McKeown, 2012).

Adaptability is considered as the ability of a (computer) system to adapt itself efficiently and fast to certain changed circumstances. An adaptive system is an open system that is able to fit its behavior according to changes in its environment (or even in certain parts of the system itself). Adaptive algorithms can also be used in a wide spectrum of applications, such as communications, control, filtering, (biomedical) signal processing, etc., with special emphasis to their characteristic ability to adapt in unknown and changing environments.

Adaptive algorithms can be classified into two main categories, namely the deterministic approach and the stochastic approach. The latter approach is mainly based on the stochastic approximation theory (for differential equations), steady state behavior and asymptotic stability analysis of adaptive algorithms (Benveniste et al., 1990; Solo et al., 1995; Kato, 1966; Haykin, 1996).

The class of adaptive algorithms includes sets of instructions in order to perform functions that can adapt in the events of changes in environments of circumstances aiming to achieve the best possible outcomes. These algorithms can be easily presented in pseudoalgorithmic forms and be programmed in a number of programming languages by changing their behavior if they sense a necessity to do so.

This category of algorithms can learn from the corresponding behavior of users and can customize their results to the special needs of the users. During the coding of the adaptive algorithms a list of parameters is usually developed in order to describe what is needed to do and how. By using such adaptive versions the designer can include in his proposed adaptive algorithmic scheme certain situations that could arise and accordingly the code can be redesigned so the adaptive algorithms can learn from their experiences (Benveniste et al., 1990; Solo et al., 1995)

Adaptive algorithms can achieve performance close to theoretical ideal algorithms and guarantee most of the times stable numerical results for a wide range of workload scenarios in several social network services (Canali et al., 2010) The two most common Adaptive Algorithms are the Least Mean Squares Algorithm and the Recursive Least Squares Algorithm, while the majority of the other algorithms can be considered as variation of these two algorithms.

Theoretical insights of adaptive algorithms have been used in neural networks, genetic algorithms, evolutionary computation, natural computing, bioinformatics and computational biology, while interesting practical applications of neural networks using adaptive algorithms have been extensively used in process engineering, robotics, 
control, evolutionary computation (combinatorial and optimization problems), machine learning and heuristics, hybrid intelligent systems, soft computing applications. Further related research is devoted to quantum computation, pattern recognition (by using kernel based algorithms), intelligent signal processing and computer vision (Ribeiro et al., 2005).

It has been recently reported that adaptive computation can be efficiently used in Artificial Intelligence, computational Geometry, Biometric Technologies. The adaptive algorithms can be applied to surface modelling, biometric processing especially in the cases of massive data storage and very large datasets of collected data (such as Geographic Information Systems [GIS] maps, biometric samples, videos etc.), faster processing and precise visualization or optimizing existing algorithms (Gavrilova, 2009).

\section{The Uncertainty Principle}

The Uncertainty principle is extensively used in various methodologies and techniques in a wide spectrum of scientific and technological fields, including physics, statistics, engineering, information science, economics, finance, sociology, philosophy, psychology, insurance. It is applicable to predictions of future events in particular to existing physical measurements or to the unknown. Due to the its very significant importance in various ways among the general public, in statistics, decision theory and other qualitative and quantitative fields there are several definitions of uncertainty, risk and their corresponding measurements (Knight, 1921; Simon, 1969; Smithson, 1989; Laffont, 1989; Folland and Sitaram, 1997; Lindley, 2006; Hubbard, 2010), such as:

(i) Uncertainty: a state of having (very) limited knowledge where it is impossible to exactly describe the existing states, future outcomes or more than one possible outcome. The term is commonly related to the lack of certainty.

(ii) Measuring of Uncertainty: A set of possible states or related outcomes, where probabilities are assigned to each possible state or related outcome (this computational procedure includes the applications of probability density functions to continuous variables).

(iii) Risk: A state of uncertainty, where several possible outcomes have undesired effects of significant losses.

(iv) Measuring of Risk: A set of measured (computed) uncertainties, where several possible outcomes are losses and the magnitudes of those losses, including loss functions over continuous variables (Hubbard, 2010).

The Uncertainty Principle in Quantum Mechanics is any of a variety of mathematical inequalities asserting a fundamental limit to the required precision with which certain pairs of physical properties of a considered particle, such as the position $\mathrm{x}$ and momentum $\mathrm{p}$, can be simultaneously known. The more precisely the position of some particle is computed, the less precisely its momentum can be known and vice versa. Heisenberg (1927) determined the existence of such limits. Note that the Uncertainty Principle states a fundamental property of the quantum systems and is not considered as a statement about the observational success of the contemporary technology.

In mathematical terms the position and momentum are conjugate variables, i.e. the uncertainty relationships between these two variables are derived due to the expressions of the wavefunction in these the two corresponding bases which should be considered as Fourier transforms of one another. On the relationships between uncertainty and adaptivity, it has been reported that although the presence of uncertainty cannot make intelligent choice impossible, it creates favorably the use of adaptive procedures instead of optimizing several strategies that work well only when finely tuned to precisely known environments (Simon, 1982).

Uncertainty can be considered as an idiomorphic aspect of knowledge accumulated by certain diagnostic systems. The basic elements of systems knowledge are content (facts and rules), relevance and confidence. Although the first two basic elements are widely exploited into several diagnostic models and related tools, the third one doesn't receive specific attention (Piccinelli et al., 2003). Uncertainty can be presented as a fundamental and dynamic component of diagnostic knowledge and processes by using fuzzy sets as theoretical base of the considered models.

In the framework of e-business performance and management science, the relationships between technology, innovation and firm performance (Koellinger, 2008), (which can be measured in terms of profitability and growth of the firm) can be shown in several adaptive algorithmic schemes (Lipitakis, 2012; Lipitakis and Lipitakis, 2012b). In the case of e-business and strategic management planning in order to demonstrate the flexibility and efficiency of both adaptability (algorithmic theory) and uncertainty (singular perturbation theory) several singular perturbation (sp)-parameters at first step-level have been used in certain adaptive algorithms leading to (near) optimized determination of the required relationships between technology, innovation and firm performance (Lipitakis and Lipitakis, 2012a).

Then, the Adaptive Hybrid Algorithmic Modeling Approach (AHAMA) can be described as follows:

\section{Algorithm AHAMA (PORT, PHIL, DARE, THEO, LIPI, AHAMS)}

Purpose: describes an innovative Adaptive Hybrid Algorithmic Modeling Approach, the so-called AHAMA methodology, for solving a wide class of e-business and strategic management problems under uncertainty conditions.

Input: Forces Analysis FAN, Design Structure STR, Leadership LEA, People and Culture PCU, Coherence COH, Knowledge KNO, Alliances ALL, Agility \& Decision Making ADM. 
Transformative Research and Innovations TRI, Multidisciplinary Research and Technology MRT, New Paradigms and Fields NPF, Future Cooperation for Research and Education FCRE, Economic system of Synergy ESS, Adaptability and Uncertainty AAU

Output: The Adaptive Hybrid Algorithmic Model Solution (AHAMS)

\section{Computational Procedure:}

Module 1-PORT (FAN)

Step 1: Forces Analysis FAN (TSP, TENC, ICR, BPC, BPS, CCO)

Step 1.1: Threat of substitute products TSP (BPS, RPPS, BSC, PLPF) (BPS)

Step 1.1.1: Buyer prosperity to substitute

Step 1.1.2: Relative price performance of substitutes (RPPS)

Step 1.1.3: Buyer switching costs (BSC)

Step 1.1.4: Perceived level of product differentiation (PLPF)

Step 1.2: Thread of the entry of new competitors TENC (EBE, EPD, BEQ, SCSC, CRE, ADI, ACA, LCA, ERI, GPO)

Step 1.2.1: existence of barriers to entry (patents, rights etc) (EBE)

Step 1.2.2: economies of product differences (EPD)

Step 1.2.3: brand equity (BEQ)

Step 1.2.4: switching costs or sunk costs (SCSC)

Step 1.2.5: capital requirements (CRE)

Step 1.2.6: access to distribution (ADI)

Step 1.2.7: absolute cost advantages (ACA)

Step 1.2.8: learning curve advantages (LCA)

Step 1.2.9: expected retaliation by incumbents (ERI)

Step 1.2.10: government policies (GPO)

Step 1.3: Intensity of competitive rivalry ICR (NCO, RIG, IIO, EBA, DOC, ICA, FCA, LAE, EOS, SCAI)

Step 1.3.1: number of competitors (NCO)

Step 1.3.2: rate of industry growth (RIG)

Step 1.3.3: intermittent industry overcapacity (IIO)

Step 1.3.4: exit barriers (EBA)

Step 1.3.5: diversity of competitors (DOC)

Step 1.3.6: informational complexity and asymmetry (ICA)

Step 1.3.7: fixed cost allocation per value added (FCA)

Step 1.3.8: level of advertising expense (LAE)

Step 1.3.9: economies of scale (EOS)

Step 1.3.10: sustainable competitive advantage through improvisation (SCAI)
Step 1.4: Bargaining power of customers BPC (BCFC, DDCD, BLIC, BVO, BSCF, BIA, ABI, AESP, BPS, DAIP, ARFM)

Step 1.4.1: buyer concentration to firm concentration ration (BCFC)

Step 1.4.2: degree of dependency upon existing channels of distribution (DDCD)

Step 1.4.3: bargaining leverage particularly in industries with high fixed costs (BLIC)

Step 1.4.4: buyer volume (BVO)

Step 1.4.5: buyer switching costs relative to firm switching costs (BSCF)

Step 1.4.6: buyer information availability (BIA)

Step 1.4.7: ability to backward integrate (ABI)

Step 1.4.8: availability of existing substitute products (AESP)

Step 1.4.9: buyer price sensitivity (BPS)

Step 1.4.10: differential advantage (uniqueness) of industry products (DAIP)

Step 1.4.11: analysis RFM (ARFM)

Step 1.5: Bargaining power of suppliers BPS (SSCF, DDI, PSI, SCFC, ESO)

Step 1.5.1: supplier switching costs relative to firm switching costs (SSCF)

Step 1.5.2: degree of differentiation of inputs (DDI)

Step 1.5.3: presence of substitute inputs (PSI)

Step 1.5.4: supplier concentration to firm concentration ratio (SCFC)

Step 1.5.5: employer solidarity ( labour unions etc) (ESO)

Step 1.6: Consider the complementors $\mathrm{CCO}$ (GNR, PUB, PGR)

Step 1.6.1: government (national and regional) (GNR)

Step 1.6.2: public (PUB)

Step 1.6.3: pressure groups (PGR)

Module 2-PHIL (STR, LEA, PEC, COH, KNO, ALL, ADM)

Step2: Design Structure STR (MRE, POR, SAR, DBF)

Step 2.1: Managing Relationships (MRE)

Step 2.2: Process Orientation (POR)

Step 2.3: Strategic Architecture (SAR)

Step 2.4: Demand based Flexibility (DBF)

Step 3: Improve Leadership LEA (TCH, LAD, LAC, LEIS)

Step 3.1: Transformation Champion (TCH)

Step 3.2: Leadership Advocacy (LAD)

Step 3.3: Leadership Accountability (LAC)

Step 3.4: Leadership Empowerment \& Idea Synthesis (LEIS)

Step 4: Focus on People and Culture PCU (REW, RCR, LRE, RTR, ICO) 
Step 4.1: Rewards (REW)

Step 4.2: Rapid Customer Responsiveness (RCR)

Step 4.3: Learning \& Renewal (LRE)

Step 4.4: Respect \& Trust (RTR)

Step 4.5: Involvement \& Commitment (ICO)

Step 5: Emphasize on Coherence COH (MPE, III, SIN, DDS, CCS)

Step 5.1: Measurements \& Performance Evaluation (MPE)

Step 5.2: Integrated Information Infrastructure (III)

Step 5.3: Standardisation \& Interoperability (SIN)

Step 5.4: Decentralised Differentiated Services (DDS)

Step 5.5: Common Centralised Services (CCS)

Step 6: Comment on Knowledge KNO (KDA, KFO, KEM, KAC, KSH)

Step 6.1: Knowledge Development Applications (KDA)

Step 6.2: Knowledge Focus (KFO)

Step 6.3: Knowledge Exchange Meetings (KEM)

Step 6.4: Knowledge Accessibility (KAC)

Step 6.5: Knowledge Sharing (KSH)

Step 7: Determine Alliances ALL (ART, APE, CRI)

Step 7.1: Alliance Respect \& Trust (ART)

Step 7.2: Alliance Performance Expectations (APE)

Step 7.3: Complexity \& Risk (CRI)

Step 8: Focus on Agility \& Decision Making ADM (IRE, MSR, TRTO, PMA, MSA, ADE)

Step 8.1: Intent Realisation (IRE)

Step 8.2: Matching and Speed \& Risk (MSR)

Step 8.3: Tempo/Reliability Trade off (TRTO)

Step 8.4: Project Management (PMA)

Step 8.5: Market Space Awareness (MSA)

Step 8.6: Agility \& Decision Edge (ADE)

Module 3-DARE (TRI, MRT, NPF, FCRE)

Step 9: Transformative Research and Innovations TRI (TII, TTAI, TEA, TNKNR, TIP)

Step 9.1: Transformative inspirations and ideas (TII)

Step 9.2: Transformative technical approaches, technical processes \& Infrastructures (TTAI)

Step 9.3: Transformative educational activities (TEA)

Step 9.4: Transformative networks of knowledge, networks of researchers \& Partnerships (TNKNR)

Step 9.5: Transformation inducing programs (TIP)

Step 10: Multidisciplinary Research and Technology MRT (MCO, NCA)

Step 10.1: multidisciplinary co-operations in science \& engineering, business management, marketing, finance and social sciences (MCO)
Step 10.2: novel capabilities resulting from complex interactions in multi-model \& multi-data (NCA)

Step 11: New Paradigms and Fields NPF (CIN, UCI, DDAS)

Step 11.1: Cyber-Infrastructures, e-Infrastructures for support for fundamental/applied research (CIN)

Step 11.2: Ubiquitous Computing, instrumentation and censoring (UCI)

Step 11.3: Dynamic Data driven applications systems and symbiotic feedback of computations $\&$ measurements (DDAS)

Step 12: Future Cooperation for Research and Education FCRE (CAP, MTME, MGL, ARIP, CIN)

Step 12.1: Cooperation approach of University-Industry-Government (CAP)

Step 12.2: Multidisciplinary and transformative modality of research and technological advances (MTME)

Step 12.3: multidimensional globalization including innovation, production, distribution and delivery of goods (MGL)

Step 12.4: academic research and industry prototypes (ARIP)

Step 12.5: Competitiveness initiatives and new framework program series (CIN)

Module 4-BRYN (CADB, OPIA, UEVI, UMBI, ICOC, IPQP, IHUC)

/Converting technology to productivity: since Information Technology and high-performance digital organization lead to high levels of productivity growth of companies in the following we present certain fundamental productivity components//

Step 13: convert analogue business processes to digital business (CADB)

Step 14: encourage open information access (OPIA)

Step 15: use economic value of information and empower accordingly the employees (UEVI)

Step 16: use merit-based incentives in order to motivate employees (UMBI)

Step 17: Invest in corporate culture (ICOC)

Step 18: Recruit the right qualified people in order to improve the productivity (IPQP)

Step 19: Apart of the previous 6 practices also invest in human capital (IHUC)

Module 5-THEO (ESS)

Step 20: Economic system of Synergy ESS (HNE, RFP, SYA, HPG, SNW)

Step 20.1: Household needs (HNE)

Step 20.2: Resources or factors of production (RFP)

Step 20.3: The synergy of all (SYA)

Step 20.4: The highest production and growth (HPG) 
Step 20.5: Satisfying needs and welfare (SNW)

Module 6-LIPI (AAU)

Step 21: Adaptability and Uncertainty AAU (ACO, $\mathrm{UCO})$

Step 21.1: Determine the adaptive weighted coefficients and proceed with the Adaptive computing (ACO)

Step 21.2: Determine the singular perturbation parameters and consider the existing Uncertainty conditions (UCO)

Step 22: Print the Adaptive Hybrid Algorithmic Model Solution AHAMS

The proposed basic modules of the AHAMA algorithm, including the adaptivity and uncertainty principles module, are considered to be the critical factors affecting the e-business performance and strategic management methodologies of various DIM applications.

\section{An Optimized Adaptive Algorithmic Schemes for e-services}

An optimized adaptive algorithm, the so-called Optimized Adaptive Hybrid Algorithmic Modelling Approach (OAHAMA), can be designed by calling the corresponding dynamic algorithmic procedure AHAMA in the following manner:

Algorithm OAHAMA ( $\varepsilon_{\text {PO }}$ PORT, $\varepsilon_{\text {PH }}$ PHIL, $\varepsilon_{D A}$ DARE, $\varepsilon_{\mathrm{BR}}$ BRYN, $\varepsilon_{\mathrm{TH}}$ THEO, $\varepsilon_{\mathrm{LI}}$ LIPI, $\varepsilon_{\mathrm{UF}}$ AHAMS)

Purpose: describes an Optimized Adaptive Hybrid Algorithmic Modeling Approach, the so-called OAHAMA methodology, for solving a wide class of e-business and strategic management problems under uncertainty conditions.

Input: Forces Analysis FAN, Design Structure STR, Leadership LEA, People and Culture PCU, Coherence COH, Knowledge KNO, Alliances ALL, Agility \& Decision Making ADM, Transformative Research and Innovations TRI, Multidisciplinary Research and Technology MRT, New Paradigms and Fields NPF, Future Cooperation for Research and Education FCRE, Economic system of Synergy ESS, Adaptability and Uncertainty AAU, sp-parameters

$$
\varepsilon_{\mathrm{PO}}, \varepsilon_{\mathrm{PH}}, \varepsilon_{\mathrm{DA}}, \varepsilon_{\mathrm{BR}}, \varepsilon_{\mathrm{TH}}, \varepsilon_{\mathrm{LI}}, \varepsilon_{\mathrm{UF}}
$$

Output: The Optimized Adaptive Hybrid Algorithmic Model Solution ( $\varepsilon_{\mathrm{UF}}$ AHAMS)

Computational Procedure:

Module 1: $\varepsilon_{P O}$ PORT (FAN)

Module 2: $\varepsilon_{P H}$ PHIL (STR, LEA, PEC, COH, KNO, ALL, $A D M)$

Module 3: $\varepsilon_{D A}$ DARE (TRI, MRT, NPF, FCRE)

Module 4: $\varepsilon_{B R}$ BRYN (CADB, OPIA, UEVI, UMBI, ICOC, IPQP, IHUC)

Module 5: $\varepsilon_{T H}-T H E O$ (ESS)

Module 6: $\varepsilon_{L I}$-LIPI (AAU)

Compute the uncertainty factor parameter $\varepsilon_{U F}$ and
Print the Optimized Adaptive Hybrid Algorithmic Model Solution ( $\left.\varepsilon_{U F} A H A M S\right)$

Note that the components of the modules' arguments can be computed by considering the optimized forms of the corresponding components of the AHAMA methodology in combination with the singular perturbation (sp)-parameters. The sp-parameters $\varepsilon \mathrm{PO}, \varepsilon \mathrm{PH}, \varepsilon \mathrm{DA}, \varepsilon \mathrm{TH}, \varepsilon \mathrm{LI}$ are applied respectively to the input parameters and $\varepsilon U F$ (the uncertainty factor parameter) is applied to the output of the algorithm AHAMA of section 3. These sp-parameters are determined in the course of the computational procedure. Then the computational procedure of the algorithm OAHAMA can be easily constructed by following the corresponding part of the algorithm AHAMA.

The values of the sp-parameters affecting the corresponding input variables of the optimized algorithm OAHAMA can be determined experimentally or approximately from corresponding appropriate mathematical model. It should be noted that the algorithm AHAMA of section 3 can be considered as a special case of the algorithm OAHAMA for the choice of sp-parameters

$$
\varepsilon_{\mathrm{PO}}=\varepsilon_{\mathrm{PH}}=\varepsilon_{\mathrm{DA}}=\varepsilon_{\mathrm{TH}}=\varepsilon_{\mathrm{LI}}=1
$$

The selection of the appropriate sp-parameters leading to (nearly) optimized solutions is dependent on the nature of the considered problem and often requires extensive experimentation.

The main advantage of the proposed algorithmic approach is twofold. Firstly, the adaptive algorithms can be efficiently used for solving a wide class of e-business and strategic management problems, and secondly the dynamical choice of the sp-parameter values, which can be related to both quantitative and qualitative nature of the input parameters (data) of the given problem, can lead to (near) optimum solutions.

\section{A generalized Time-dependent Model for Evaluating a Firm E-business Performance}

Since the repetitive computational procedure for the evaluation of e-business Performance $P$ over a certain period of time is by nature a time-dependent problem, the following conceptual generalized model for computing the performance $\mathrm{P}$, can be proposed:

$$
\begin{array}{r}
\partial \mathrm{P}_{\mathrm{i}, \mathrm{j}}{ }^{(\mathrm{t})} / \partial \mathrm{t}=\mathrm{f}\left(\mathrm{m}_{\mathrm{i}, \mathrm{j}}{ }^{\mathrm{t}}, \mathrm{u}_{\mathrm{i}, \mathrm{j}}{ }^{\mathrm{t}}, \mathrm{e}_{\mathrm{i}, \mathrm{j}}{ }^{\mathrm{t}}, \mathrm{SM}^{\mathrm{t}}\right)-\mathrm{P}_{\mathrm{i}, \mathrm{j}}{ }^{(\mathrm{t})}+\mathrm{Q}_{\mathrm{i}, \mathrm{j}}{ }^{(\mathrm{t})}, \\
0<\mathrm{t} \leq \mathrm{T}
\end{array}
$$

where $i=1,2, \ldots, N, j=1,2, \ldots, J$, with $N$ the number of heterogeneous firms, $\mathrm{J}$ the number of different markets and $\mathrm{k}=[1(1) 5]$ the indices indicating the corresponding modules $\mathrm{M}_{\mathrm{k}}$ of the adaptive algorithmic procedure AHAMA of section 4 .

The performance $\mathrm{P} \equiv \mathrm{P}_{\mathrm{i}, \mathrm{j}}{ }^{(\mathrm{t})}$ is a function of the independent variables, namely the observable firm 
characteristics $\mathrm{m}$, and the unobservable error terms $\mathrm{u}$ and e. Specifically, $\mathrm{m}_{\mathrm{i}, \mathrm{j}}{ }^{\mathrm{t}}$ includes several observable firm characteristics for a market $j$, while the index $i$ corresponds to innovation activities $(\mathrm{i}=1)$, firm size $(\mathrm{i}=2)$, market share $(i=3)$, employees with university degree $(i=4)$, number of e-business technologies in the firm $(i=5)$, over a certain time-period t.

The unobservable error term $u_{j}$ is equal for all firms operating in market $j$ (but they can vary and can be dependent on the firm specific effect $e_{i, j}{ }^{t}$. The unobservable error term $\mathrm{e}_{\mathrm{i}, \mathrm{j}}{ }^{\mathrm{t}}$ captures all relevant firm specific unobserved effects, is independent of all observable factors $m_{i, j}{ }^{t}$ by assumption, on certain time-period t, while $\mathrm{Q}$ is a source term (with $\mathrm{Q}=0$ when $\mathrm{t}=0$ ). In the case that $\mathrm{t}=0$ (steady-state) the proposed firm performance model (5.1) reduces to a static model of firm performance (Koellinger, 2008). The term $\mathrm{SM}^{\mathrm{t}}=\sum_{k=1}^{6} \mathrm{M}_{\mathrm{k}}$ corresponds to the modules $\mathrm{M}_{\mathrm{k}}$, $\mathrm{k}=1(1) 6$ at a certain time $t$, i.e. the corresponding modules $\mathrm{M}_{\mathrm{k}}$ of the adaptive algorithmic procedure AHAMA, which are successively defined as $\mathrm{M}_{\mathrm{k}}=$ module $\mathrm{k}, \mathrm{k}=1,2, \ldots, 6$, i.e.

$$
\begin{gathered}
\mathrm{M}_{1}=\text { Module 1-PORT (FAN) } \\
\mathrm{M}_{2}=\text { Module 2-PHIL (STR, LEA, PEC, COH, } \\
\text { KNO, ALL, ADM) } \\
\mathrm{M}_{3}=\text { Module 3-DARE (TRI, MRT, NPF, FCRE) } \\
\mathrm{M}_{4}=\text { Module 4-BYRN ((CADB, OPIA, UEVI, } \\
\quad \text { UMBI, ICOC, IPQP, IHUC) } \\
\mathrm{M}_{5}=\text { Module 5THEO (ESS) } \\
\mathrm{M}_{6}=\text { Module 6-LIPI (AAU) }
\end{gathered}
$$

with the arguments of the above modules defined in the algorithm AHAMA of section 3.

The efficiency and validation of the proposed theoretical time-dependent performance evaluation model requires further empirical evidence from a class of e-business organizations and extensive numerical experimentation with corresponding statistical analysis for computing the firm performances.

By considering the evaluation of a firm e-business performance as a time-dependent problem the investigation of the performance stability over a certain period of time, seems to be a challenging future research problem.

\section{Conclusions}

This research work was based on key-field concepts of four interrelated sciences, i.e. Computer Science (adaptive algorithmic theory), Applied Mathematics (singular perturbation theory and partial differential equations) and Management Science (strategic management and e-business).

The adaptive dynamic algorithmic approach and singular perturbation concept have been applied for solving efficiently several e-business problems. A class of characteristic case studies has been presented and their corresponding adaptive algorithmic schemes are given. Furthermore, the adaptability and compactness of the proposed algorithms through the choice of singular perturbation parameters lead to an (near) optimum solution of the considered e-business performance case studies.

It is envisaged that future empirical evidence from the proposed e-business adaptive algorithms by using the extensive numerical experimentation and corresponding statistical analysis will show the full advantages of the adaptive algorithmic modelling and the relationships between e-technology, product and process innovations and e-business performance. The study of the stability of e-business and e-services performance could be also a significant related research topic.

The choice of the singular perturbation parameters, leading to efficient solutions, is an interesting open problem of future research work. The proper choice is closely related to both quantitative and qualitative nature of the input parameters (data) of the given problems and their corresponding dynamical algorithms can lead to (near) optimum solutions of a wide area of e-business problems, e-services and related applications.] $\backslash$

\section{Acknowledgements}

The authors wish to thank the reviewers for their constructive criticisms

\section{REFERENCES}

[1] ANDRESEN K. and GRONAU N. (2005): An Approach to Increase Adaptability in ERP Systems. In: Managing Modern Organizations with Information Technology, Proceedings of the 2005 Information Resources Management Association International Conference, 2005.

[2] ANDRESEN K.: Design and Use Patterns of Adaptability in Enterprise Systems, Gito, Berlin 2006, S. 52

[3] BABUSKA I., NOBILE F. and TEMPONE R. (2005): Worst case scenario analysis for elliptic problems with uncertainty, Numerische Mathematik 101, 185-219

[4] BARR P.S., STIMPERT J.L, and HUFF A.S. (1992): Cognitive Change, Strategic Action, and Organizational Renewal, Strategic Management Journal 13 (Special Issue), 15-36.

[5] BENVENISTE A., METIVIER M. and PRIOURET P.: Adaptive Algorithms and Stochastic Approximations, Springer, New York, 1990

[6] BRYNJOLFSSON E. (1993): The Productivity Paradox of Information Technology, Communications of ACM 36, $67-77$

[7] BRYNJOLFSSON E. (2005): VII Pillars of Productivity, Optimize, Issue 22, May 2005

[8] BRYNJOLFSSON E. and HITT L. (2000): Beyond 
Computation: Information Technology, Organizational Transformation and Business Performance, Journal of Economic Perspectives 14 (4), 23-48.

[9] BYRON W.K., SZARO R.C. and SHAPIRO C.D. (2007): Adaptive Management: The U.S. Department of the Interior Technical Guide, US Department of the Interior.

[10] CANALI C., COLAJANNI M. and LANCELLOTI R.(2010): Adaptive Algorithms for Efficient Content Management in Social Network Services, Procs. 10th IEEE International Conference on Computer and Information Technology, CIT 2010, Bradford, West Yorkshire, UK.

[11] CARTON R. and HOFER C. (2005): Organizational financial performance: Identifying and testing multiple dimensions, Proceedings of the 50th International Council for Small Business World Conference, Washington DC.

[12] CARTON R.B. and HOFER C.W.: Measuring Organizational Performance: Metrics for Entrepreneurship and strategic Management research, Edward Elgar Publishing Inc., UK-USA, 2006.

[13] CHAFFE E.E. (1985): Three Models of Strategy, Academy of Management Review 10(1), 89-99.

[14] COLTMAN T., DEVINNEY T.M. and MIDGLEY D.F. (2007): e-business strategy and firm performance: a latent class assessment of the drivers and impediments to success, Journal of Information Technology 22, 87-101.

[15] COLTMAN T., DEVINNEY T.M. and MIDGLEY D.F. (2008): The value of managerial beliefs in turbulent environments: Managerial orientation and e-business advantage, Research Online, http://ro.uow.edu.au/infopapers/687

[16] COLTMAN T., DEVINNEY T.M., MIDGLEY D. and VENAIK S. (2008): Formative versus reflective measurement models: Two applications of formative measurement, Journal of Business Research (JBR), New York, Elsevier, Vol. 61 (12), 1250-1262

[17] CONRAD M.: Adaptability, the Significance of Variability from Molecule to Ecosystem, Plenum Press, New York, 1983.

[18] DAREMA F. (2009): Transformation inducing directions in Academe and Industry, HERCMA 2009 Conference Procs., LEA Publishers, Athens, Greece

[19] DUTTON J.E., and JACKSON S.E. (1987): Categorizing Strategic Issues: Links to Organizational Action, The Academy of Management Review 12(1), 76-90.

[20] European Commission (2004a): The European e-Business Report, Office for Official Publications of the European Communities, Luxembourg, 234-237, $\mathrm{http} / / /$ www.ebusiness-watch.org

[21] European Commission (2004b): Innovation in Europe, Office for Official Publications of the European Communities, Luxembourg, $\mathrm{ftp} / / / \mathrm{ftp} . c o r d i s . l u / p u b /$ innovation-smes/docs/results.from.cis3 .for_eu_iceland_norway.pdf

[22] FINKLSTEIN S. and HAMBRICK D.C. (1996): Strategic Leadership: Top Executives and Their Effects on Organizations. St Paul, Printwise.
[23] FOLLAND G. and SITARAM C.A. (1997): The Uncertainty Principle: A Mathematical Survey, Journal of Fourier Analysis and Applications 3 (3), 207-238

[24] GAVRILOVA M.L. (2009): Adaptive Algorithms for Intelligent Geometric Computing, Artificial Intelligence.

[25] GRAF S. (2007): Adaptivity in Learning Management Systems Focussing on Learning Styles, Ph.D. Thesis, Vienna University of Technology, Austria

[26] GROTE G.: Management of Uncertainty: Theory and Application in the Design of Systems and Organizations, Decision Engineering, 2009

[27] HAFEEZ K., KEOY K.H. and HANNEMAN R. (2006): E-Business capabilities model: Validation and comparison between adopter and non-adopter of e-business companies inUK, Journal of Manufacturing Technology Management $17,806-828$

[28] HALPERN J. : Reasoning about Uncertainty, MIT Press, 2005

[29] HAYKIN S.: Adaptive Filter Theory, 3-rd edn, Prentice-Hall, Englewood Cliffs, NJ, 1996

[30] HEISENBERG W. (1927): Über den anschaulichen Inhalt der quantentheoretischen Kinematik und Mechanik, Zeitschrift für Physik 43: 172-198, doi:10.1007/BF01397280, English translation: J. A. Wheeler and H. Zurek, Quantum Theory and Measurement Princeton Univ. Press, 1983, 62-84.

[31] HEISENBERG W. (1930): Physikalische Prinzipien der Quantentheorie, Leipzig: Hirzel English translation The Physical Principles of Quantum Theory. Chicago: University of Chicago Press, 1930.

[32] HOLLING C. S. (ed.): Adaptive Environmental Assessment and Management, Chichester: Wiley, 1978

[33] HUBBARD D.: How to Measure Anything: Finding the Value of Intangibles in Business, 2nd ed. John Wiley \& Sons, 2010

[34] KAHNEMAN D., TVERSKY A. and SLOVIC P., eds. (1982): Judgment under Uncertainty: Heuristics \& Biases, Cambridge, UK, Cambridge University Press.

[35] KAREAL F. and KLEMA J. (2006): Adaptivity in e-learning, Current Developments in Technology-Assisted Education, 260-264

[36] KATO T.: Perturbation Theory for Linear Operators, Springer, New York, 1966.

[37] KNIGHT F.H.: Risk, Uncertainty and Profit, Boston, MA: Hart, Schaffner \& Marx; Houghton Mifflin Company, 1921

[38] KNUTH D.E.: The Art of Computer Programming, Volume 1: Fundamental Algorithms, Addison-Wesley Publ. Co., Reading, Massachusetts, Amsterdam-London-Tokyo, 1968

[39] KOELLINGER P. (2008): The relationship between technology, innovation and firm performance- Empirical evidence from e-business in Europe, Research Policy 37, $1317-1328$

[40] LAFFONT J.-J. : The Economics of Uncertainty and Information, MIT Press, 1989. 
[41] LENZ R.T. (1981): Determinants' of organizational performance: an interdisciplinary review, Strategic Management Journal 2, 131-154

[42] LINDLEY D.V.: Understanding Uncertainty. Wiley-Interscience, 2006

[43] LIPITAKIS A. (2007a): Adaptive Algorithmic Methods and Dynamical Singular Perturbation Techniques for Strategic Management Methodologies, HERCMA 2007 Conference Procs, LEA Publishers, Athens, Greece

[44] LIPITAKIS A. (2007b): Adaptive algorithmic schemes for e-service strategic management methodologies: Case studies on Knowledge Management, ICEBE/ SOKM 2007 Conference Procs, IEEE Intl. Conference on E-Business Engineering, October 2007, Hong Kong, China

[45] LIPITAKIS A. (2012): E-Business Strategy Planning and Performance: A Comparative Study of the UK and Greece, Ph.D. Thesis, KBS, University of Kent at Canterbury, England

[46] LIPITAKIS A. and LIPITAKIS E.A.E.C. (2012a): E-business and Strategic Management: E-valuation Quality Performance based on ADAM Methods, ICCGI 2012 Conference Proceedings, July 2012, Venice, Italy

[47] LIPITAKIS A. and LIPITAKIS E.A.E.C. (2012b): On the e-Valuation of Certain e-Business Strategies on Firm Performance by Adaptive Algorithmic Modeling: An Alternative Strategic Managerial Approach, Journal of Computer Technology and Application (JCTA) 3 (1), 38-46

[48] LIPITAKIS A. and PHILLIPS P. (2007): E- Business Strategies and Adaptive Algorithmic Schemes, HERCMA 2007 Conference Procs., LEA Publishers, Athens, Greece

[49] LIPITAKIS E.A.: A universal iterative solver based on the Euclid's algorithm for the numerical solution of general type Partial Differential Equations, in 'Computer Mathematics and its Applications', 597-642, LEA Publishers, Athens, 2006.

[50] McKEOWN M.: Adaptability: The Art of Winning, Kogan Page, 2012

[51] MONTGOMERY C.A. (2008): Putting Leadership Back Into Strategy, Harvard Business Review 86(1), 54-60.

[52] NOHRIA N., JOYCE W. and ROBERSON B. (2003); What Really Works?, Harvard Business Review. 81(7), 42-52.

[53] NSF (National Science Fundation) Strategic Plan 2006-2011

[54] OPPERMANN R. (2005): User-Adaptive to Context-Adaptive Information Systems, i-com Zeitschrift für interaktive und kooperative Medien 4 (3), 4-14.

[55] PARAMYTHIS A., LOIDL-REISINGER S. (2004): Adaptive Learning Environments and e-Learning Standards, Electronic Journal of E-learning, Vol. 2, Issue 2, 2004

[56] PELLETIER D., TURGEON E. and LACASSE D. (2003): Adaptivity, sensitivity, and uncertainty: Toward standards of good practice in computational fluid dynamics, AIAA Journal 41, 1925-1933

[57] PHILLIPS P. (2009): Organizational Flexibility: The Seven

[58] Factors of Success in E-Business Environments, HERCMA 2009 Conference Procs., LEA Publishers, Athens, Greece
[59] PICCINELLI G. and CASASSA MONT M. (1998): An Adaptive Model for Explicit Uncertainty Management, Extended Enterprise Laboratory, HP Laboratories Bristol, HPL-98-33, 1-11

[60] PICCINELLI G., ZIRPINS C. and GRYCE C. (2003): A provision centric model for electronic services, in IEEE International workshops on enabling technologies: Infrastructure for collaborative enterprises (WETICE 2003) IEEE Computer Society, 113-116

[61] POLYA G. (1945): How To Solve It: A New Aspect of Mathematical Method, Princeton, NJ: Princeton University Press.

[62] PORTER M. (2001): Strategy and the Internet, Harvard Business Review 79, pg 62

[63] PORTER M.: Competitive Strategy, Free Press, New York, 1980

[64] PORTER M.: How competitive forces shape strategy, Harvard Business Review, April 1979

[65] RAIBULET C. (2008): Facets of Adaptivity, Proceedings of the 2ndEuropean Conference on Software Architecture, Lecture Notes in Computer Science LNCS 5292, 342-345

[66] RAIBULET C. and MASCIADRI L. (2009): Evaluation of Dynamic Adaptivity Through Metrics: an Achievable Target? IEEE/ IFIP WICSA/ECSA, 341-344

[67] RASHEV R. and KINSHUK R.R. (1997): Adaptability and Adaptivity in Learning Systems, In A. Behrooz (Ed.): Proceedings of the International Conference on Oppermann Knowledge Transfer, London, Pace, Vol. 2, 173-179.

[68] RIBEIRO B., ALBRECHT R.F., DOBNIKAR A., PEARSON D.W. and STEELE N.C. (Eds) (2005): Adaptive and Natural Computing Algorithms: Proceedings of the International Conference in Coimbra, Portugal, Springer Computer Science

[69] ROBERTSON H. P. (1929): The Uncertainty Principle, Phys. Rev. 34, 163-64.

[70] SHANNON C. (1948)/(1949): A mathematical theory of communication, Bell System Tech. J. 27, 379-423, and 623-656 (Reprinted in: Shannon, C. and Weaver, W., The Mathematical Theory of Communication, Univ. of Illinois Press, Urbana. MR10, 133e), American Physical Society online exhibit on the Uncertainty Principle.

[71] SIMON H.A.: The Sciences of the Artificial, Third Edition, MIT Press, p.35, 1969.

[72] SIMON H.A.: Models of Bounded Rationality, MIT Press, Cambridge, Massachusetts, 1982.

[73] SMITHSON M. (1989): Ignorance and Uncertainty: emerging paradigms, Bammer-Smithson (eds) Tackling wicked problems: using the transdisciplinary perspectives, Earthscan, London, 13-25

[74] SOLO V. and KONG X: Adaptive Signal Processing Algorithms, Stability and Performance, Prentice-Hall, Englewood Cliffs, NJ, 1995.

[75] SPAIS G.S. and THEOFANIDES S.M. (2005): An archetypal analysis for the development of a generalized decision-making model in groups as a prerequisite for 
productive government and leadership, Journal of Business Case Studies 1, 49-66

[76] SUBRAMANIAN N. and CHUNG L. (1999): Metrics for Adaptability, Journal of Applied Technology Division, 95-108

[77] TEECE D. (2006): Reflections on Profiting from innovation, Research Policy 35, 1131-1146

[78] TEECE D. J., PISANO G. and SHUEN A. (1997): Dynamic Capabilities and Strategic Management, Strategic Management Journal 18 (7), 509-33OFANIDES S. (1999): From Democracy to Sophocracy: A wiser political system for the 21 st century-Towards a 9, Ig. 82, IWVWW Berlin.

[79] THEOFANIDES S. (1999): The Olympian style of Management: The first model of decision making at the top better politico-economic system at the hands of Knowledgeable (Sophos) rather than the mediocre, Berichte, 5th international conference Proceedings: Integrating Technology \& Human Decisions-Global bridges into the 21 st century, vol. 1,780

[80] THEOFANIDES S. (2002): A new growth theory: The synergic efficiency of the factors of production, Taiwan Journal of Political Economy, 3:2, 15-53

[81] TIKHONOV A.N. (1936): Functional equations of Volterra type and their applications to Mathematical Physics, Doctoral Dissertation, Moscow State University.

[82] TIKHONOV A.N. and ARSENIN V.Y. (1963): Methods for solving ill-posed problems, Doklady AN SSSR 153, 1.

[83] WALTERS C.: Adaptive Management of Renewable Resources, New York: Macmillan, 1986

[84] WEILL P. and VITALE M.R. (2001): Place to Space: Migrating to e-Business Models, Harvard Business School Press, Cambridge, MA

[85] WHEELER B.C. (2002): NEBIC: a dynamic capabilities theory for assessing Net-enablement, Information Systems Research 13, 125-146

[86] ZADEH L.A.: The role of fuzzy logic in the management of Uncertainty in Expert Systems, in Fuzzy Set and Systems 11, North Holland, 1983.

[87] ZAJAC E.J., KRAATZ M.S, and BRESSER R.K.F. (2000): Modeling the Dynamics of Strategic Fit: A Normative Approach to Strategic Change, Strategic Management Journal 21(4), 429-453.

[88] ZANAKIS S.H., THEOFANIDES S., KONTARATOS A.N. and TASSIOS T.P. (2003): Ancient Greeks' practices and contributions in Public and Entrepreneurship decision making, Interfaces (INFORMS) 33, 72-88 